\title{
AVALIAÇÃO DE DESEMPENHO DA APHANOTHECE MICROSCOPICA NÄGELI UTILIZANDO DIFERENTES CONCENTRAÇÕES DE AMIDO DE MANDIOCA COMO FONTE DE CARBONO ORGÂNICO
}

\author{
R. B. SARTORI ${ }^{1}$, A. M. SANTOS ${ }^{1}$, K. R. V. VIEIRA ${ }^{1}$, L. Q. ZEPKA ${ }^{1}$, M. I. QUEIROZ ${ }^{2}$, E. \\ JACOB-LOPES ${ }^{1}$
}

${ }^{1}$ Universidade Federal de Santa Maria, Departamento de Ciência e Tecnologia em Alimentos ${ }^{2}$ Escola de Química e Alimentos, Universidade Federal do Rio Grande (FURG)

E-mail para contato: jacoblopes@pq.cnpq.br

\begin{abstract}
RESUMO - O cultivo heterotrófico suportado por uma fonte exógena de carbono é uma importante forma de produção de metabólitos de interesse comercial, porém o alto custo de produção de biomassa microalgal é a maior barreira para sua comercialização. A escolha de insumos de baixo custo para formulação de meios de cultura é de grande importância para economia global de processos biotecnológicos, uma vez que representam um percentual significativo no custo final do produto. Neste sentido o objetivo do trabalho foi avaliar o desempenho da Aphanothece microscopica Nägeli utilizando diferentes concentrações de amido de mandioca como fonte de carbono orgânico. As condições experimentais utilizadas foram: concentração inicial de $100 \mathrm{mg} / \mathrm{L}, \mathrm{pH}$ de 7,6, temperatura de $30^{\circ} \mathrm{C}$, aeração constante de $1 \mathrm{VVM}$ (volume de ar por volume de meio por minuto), ausência de luminosidade e diferentes concentrações de amido de mandioca como fonte exógena de carbono numa razão carbono/nitrogênio de 20. Os resultados indicaram um melhor desempenho da microalga Aphanothece microscopica Nägeli utilizando a maior concentração de amido numa razão $\mathrm{C} / \mathrm{N}$ de 20 de 5000/250, atingindo produtividade celular e lipídica de $18,16 \mathrm{mg} \mathrm{L}^{-1} \mathrm{~h}^{-1} \mathrm{e}$ $3,29 \mathrm{mg} \mathrm{L}^{-1} \mathrm{~h}^{-1}$ respectivamente.
\end{abstract}

\section{INTRODUÇÃO}

As microalgas são organismos procarióticos ou eucarióticos com estruturas simples que podem crescer rapidamente e em condições adversas devido à sua estrutura unicelular (Caldeira, 2011). Um exemplo de microalgas procarióticas são as cianobactérias (ou algas cianofíceas), microorganismos preferencialmente fotossintetizantes, porém alguns destes microorganismos como a Aphanothece microscopica Nägeli possuem a distinta capacidade de substituir a fixação de $\mathrm{CO}_{2}$ atmosférico presente nas culturas autotróficas por uma fonte de carbono orgânica dissolvida no meio de cultura na ausência de luz (Perez-Garcia et al., 2011). Segundo Huang et al. (2010) neste tipo de cultivo são obtidas altas densidades celulares, proporcionando menores custos relacionados à etapa de colheita de biomassa. 


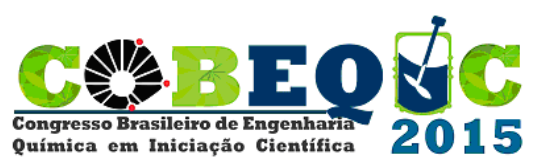

A utilização da biomassa e compostos celulares desses microorganismos vêm sendo o foco do estudo de muitos cientistas nos últimos anos, devido à identificação de diversas substâncias de alto valor agregado, que podem ser aplicados amplamente na biorremediação de águas residuais, produção de compostos bioativos, produtos de química fina para cosmética, aplicações na saúde humana, alimentação e ainda como fonte de energia (Mata et al., 2009). Mas para que a produtividade se torne economicamente viável é preciso utilizar novos sistemas de cultivos, otimizando a intensificação do processo com potencial de produzir unidades mais eficientes para aplicações em escala comercial (Wright et al., 1999).

Hornes (2010) comparou a cianobactéria Aphanothece microscopica Nägeli em dois tipos de cultivo diferentes. No efluente do processamento de pescado, utilizando glicose e cloreto de amônio como fontes de carbono e nitrogênio na ausência de luminosidade, e células em meio BG11 em ciclos claro-escuro de 12 horas. A escolha de diferentes condições de cultivo, no que se refere à iluminação do meio, foi atribuída ao fato de que, no efluente, a ausência de luz conduz ao metabolismo respiratório, comprovadamente eficiente no crescimento e produção de componentes celulares de cianobactérias (Queiroz et al., 2004; Queiroz et al., 2007; Zepka et al., 2008). A composição química das cianobactérias pode variar com a idade da cultura e com mudanças nas condições ambientais. A manipulação destes fatores pode alterar as características de crescimento e a composição química das células cultivadas nas condições aplicadas, e qualquer variabilidade associada com a fase de crescimento pode incluir também mudanças associadas à concentração de nutrientes (Lourenço et al., 1997; Fidalgo et al., 1998).

Segundo Wei et al. (2009) uma das maneiras de reduzir custos no cultivo heterotrófico está na redução dos custos do substrato. Estes autores sugerem que o uso de materiais de baixo custo, como amidos é uma boa estratégia na direção de redução de custos. Entretanto, as informações acerca da concentração inicial destas fontes de carbono necessárias para o crescimento ideal ainda são muito dispersas (Perez-Garcia et al., 2011).

Neste sentido, o objetivo do trabalho foi avaliar o desempenho (da Aphanothece microscopica Nägeli utilizando diferentes concentrações de amido de mandioca como fonte de carbono orgânico no cultivo heterotrófico.

\section{MATERIAL E MÉTODOS}

\subsection{Microorganismos e meio de cultura}

As culturas da cianobactéria Aphanothece microscópica Nägeli_RSMan92), foram originalmente isoladas do estuário da Lagoa dos Patos, Rio Grande do Sul, Brasil (3201's$\left.52^{\circ} 05^{\circ} \mathrm{W}\right)$, -foram propagadas e mantidas em meio padrão BGN, com a seguinte composição: $\mathrm{K}_{2} \mathrm{HPO}_{4}\left(3 \mathrm{~g} .100 \mathrm{~mL}^{-1}\right), \mathrm{MgSO}_{4}, 7 \mathrm{H}_{2} \mathrm{O}\left(7,5 \mathrm{~g} .100 \mathrm{~mL}^{-1}\right), \mathrm{CaCl}_{2} .2 \mathrm{H}_{2} \mathrm{O}\left(3,6 \mathrm{~g} .100 \mathrm{~mL}^{-1}\right)$, Citrato de amônio e ferro III (0,6g.100 mL-1), Na2 EDTA (0,1g.100 mL-1), NaCl (7,2g.100 mL-1), $\mathrm{NaNO}_{3}\left(150\right.$ g.L $\left.\mathrm{L}^{-1}\right)$, ácido cítrico (0,06 g.100 mL-1), $\mathrm{Na}_{2} \mathrm{CO}_{3}\left(0,2\right.$ g.100 mL $\left.\mathrm{mL}^{-1}\right), \mathrm{H}_{3} \mathrm{BO}_{3}(2,86$ g.L 1), $\mathrm{MnCl}_{2} .4 \mathrm{H}_{2} \mathrm{O}$ (1, 816 g.100 g.L-1 $), \mathrm{ZnSO}_{4} .7 \mathrm{H}_{2} \mathrm{O}\left(0.222\right.$ g.L - $\left.^{-1}\right), \mathrm{Na}_{2} \mathrm{MoO}_{4} .2 \mathrm{H}_{2} \mathrm{O}(0,390$ g.L-1 $)$,
Comentar [MM]: Incluir na revisão artigos que envolvam o crescimento deste mricroorganismo com outras fontes para comparar com seus resultados. 

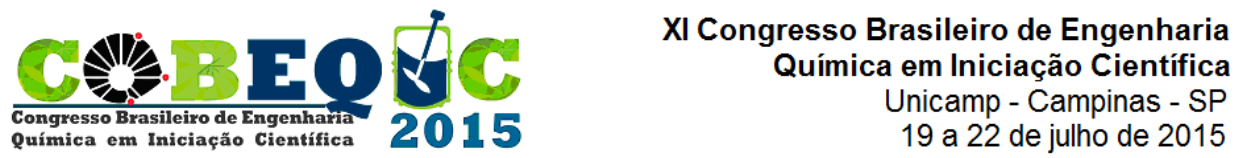
$\mathrm{CuSO}_{4} .5 \mathrm{H}_{2} \mathrm{O}\left(0,079\right.$ g.L-1), $\mathrm{CaCl}_{2} \cdot 6 \mathrm{H}_{2} \mathrm{O}(0,040$ g.L.-1). As condições de manutenção
usadas serão $25^{\circ} \mathrm{C}$ e intensidade luminosa constante de $1 \mathrm{klux}$.

\subsection{Biorreator e condições de cultivo}

Os experimentos foram conduzidos em um biorreator de coluna de bolhas com relação (altura/diâmetro)(L/D) 1,28, com difusor de tubo aberto simples de diâmetro interno de $0.9 \mathrm{~cm}$, com volume de trabalho de $2 \mathrm{~L}$. As condições experimentais foram em meio sintético BGN, adicionado de amido de mandioca visando obter uma razão C/N de $20,100 \mathrm{mg} / \mathrm{L}$ do inoculo, $\mathrm{pH}$ de 7,6 , temperatura de $30^{\circ} \mathrm{C}$, aeração contínua de $1 \mathrm{VVM}$ (volume de ar por volume de meio líquido por minuto) e ausência de luminosidade. Foram conduzidos três diferentes ensaios em meio de cultivo BGN contendo 1,55 g/L, 7,36 g/L e 12,12 g/L de amido de mandioca para as razões $\mathrm{C} / \mathrm{N}$ de 20 de $625 / 31,25,2500 / 125$ e 5000/250 respectivamente.

\subsection{Métodos analíticos}

As amostras foram coletadas em um intervalo de $24 \mathrm{~h}$ e caracterizadas quanto ao $\mathrm{pH}$, carbono orgânico total e concentração celular. $\mathrm{O}$ pH foi determinado por potenciometria, o carbono orgânico total foi determinado por um analisador de carbono TOC-L (Shimadzu, Kyoto, Japãole controlado por software TOC L Shimadzuß. A concentração celular foi determinada gravimetricamente por meio da filtração de um volume conhecido do meio de cultivo em filtro de $0,45 \mu \mathrm{m}$ de diâmetro. Os testes foram realizados em duplicata e os dados cinéticos referem-se à média de duas repetições. Ao final de cada experimento as biomassas resultantes foram coletadas e secas em estufa à $60^{\circ} \mathrm{C}$ para posterior análise de lipídeos pela técnica proposta por Bligh Dyer (1959).

\section{RESULTADOS E DISCUSSÕES}

Os dados cinéticos de produção de biomassa e consumo de substrato nas diferentes condições de razão $\mathrm{C} / \mathrm{N}$ de amido de mandioca como fonte de carbono orgânico no cultivo heterotrófico da Aphanothece microscopica Nägeli são apresentados na Tabela 1.

Tabela 1 - Parâmetros cinéticos obtidos através de diferentes proporções de carbono e nitrogênio em razões $\mathrm{C} / \mathrm{N}$ de 20

\begin{tabular}{cccc}
\hline Parâmetros & $625 / 31,25$ & $2500 / 125$ & $5000 / 250$ \\
\hline$P_{x}\left(\mathrm{mg} \mathrm{L}^{-1} \mathrm{~h}^{-1}\right)$ & 3,43 & 15,06 & 18,16 \\
$\mu_{-\operatorname{máx}}\left(\mathrm{h}^{-1}\right)$ & 0,019 & 0,0204 & 0,0486 \\
Tg (h) & 36,47 & 33,97 & 14,25 \\
Lipídio (\%) & 3,42 & 14,13 & 18,15 \\
PL $_{\text {L }}\left(\mathrm{m} \mathrm{L} \mathrm{L}^{-1} \mathrm{~h}^{-1}\right)$ & 0,11 & 2,12 & 3,29 \\
\hline
\end{tabular}


A análise dos resultados indica que a razão $\mathrm{C} / \mathrm{N}$ de $625 / 31,25$ resultou em produtividades celulares médias de $3,43 \mathrm{mg} / \mathrm{L} . \mathrm{h}$ e velocidade máxima específica de crescimento celular de $0,019 \mathrm{~h}^{-1}$. Em paralelo a biomassa apresentou um teor de lipídeos de $3,42 \%$ resultando em uma produtividade em lipídeos de $0,11 \mathrm{mg} / \mathrm{L} . \mathrm{h}$. Os resultados obtidos com razão $\mathrm{C} / \mathrm{N}$ de 2500/125 indicaram produtividades celulares médias de 15,06 mg/L.h e velocidades máximas específicas de crescimento celular de $0,0204 \mathrm{~h}^{-1}$. Nestas condições a biomassa apresentou um teor de lipídeos de $14,13 \%$ e uma produtividade em lipídeos de 2,12 $\mathrm{mg} / \mathrm{L}$.h. Já os resultados obtidos pela razão de C/N 5000/250 apresentaram uma produtividade celular média de $18,16 \mathrm{mg} / \mathrm{L}$.h e velocidade máxima específica de crescimento celular de $0,0486 \mathrm{~h}^{-1}$ onde a biomassa apresentou um teor de lipídeos de $18,15 \%$ e uma produtividade em lipídeos de 3,29 mg/L.h.

A análise dos resultados indica que a razão $\mathrm{C} / \mathrm{N}$ de 2500/125 resultou em um teor lipídico de 14,13\%. Esse valor corrobora com o estudo realizado por Francisco et al. (2015) que analisaram o cultivo heterotrófico de Phormidium sp. utilizando amido de mandioca como substrato orgânico em modo descontínuo, o que resultou em um teor lipídico de $14,38 \%$.

Bonini e Bastos (2012) utilizaram Aphanothece microscopica Nägeli em cultivo mixotrófico utilizando glicose como fonte de carbono orgânico, e obtiveram uma velocidade específica de crescimento de $0,042 \mathrm{~h}^{-1}$, o que refletiu em um tempo de geração de $16,5 \mathrm{~h}$. Esses autores consideram que $25 \mathrm{~g} / \mathrm{L}$ de glicose foi uma concentração ideal para chegar a esses resultados. Se compararmos ao estudo realizado, os resultados indicam uma velocidade específica de crescimento de $0,0486 \mathrm{~h}^{-1} \mathrm{em}$ um tempo de geração de 14,25 h utilizando 12,91 $\mathrm{g} / \mathrm{L}$ de amido de mandioca para atingir uma razão $\mathrm{C} / \mathrm{N}$ de 5000/250 em cultivo heterotrófico. Isso reflete em uma economia global no processo produtivo uma vez que é necessário um maior teor de glicose, substrato relativamente mais caro que amido de mandioca, além de períodos com luz, o que implica em gastos com energia.

A velocidade específica de crescimento máxima obtida neste estudo também é superior a obtida por Hornes et al. (2010), que avaliou o cultivo mixotrófico da Aphanothece microscopica Nägeli utilizando glicose como fonte de substrato em efluente de processamento de pescado, onde a velocidade específica de crescimento máxima foi de $0,017 \mathrm{~h}^{-1}$, com tempo de geração de $41 \mathrm{~h}$.

Para Francisco et al. (2014) o amido de mandioca e a maltodextrina são as fontes com o maior potencial de exploração para produção de biomassa e lipídeos. Segundo esses autores, as cianobactérias dispõem de uma reserva de substrato endógeno, o chamado amido cianofíceo, que serve para manter o metabolismo microalgal quando o meio de cultura apresentar uma escassez de fonte exógena de carbono. Neste sentido, as células estão totalmente adaptadas a este substrato, e a sua utilização como fonte de carbono exógeno é adequada para o crescimento heterotrófico de cianobactérias.

\section{CONCLUSÃO}

A utilização de uma maior concentração de amido de mandioca resultou em melhores desempenhos para o cultivo heterotrófico da Aphanothece microscopica Nägeli. Os resultados obtidos indicaram produtividade celular de $18,16 \mathrm{mg} / \mathrm{L} . \mathrm{h}$ com velocidade máxima específica 

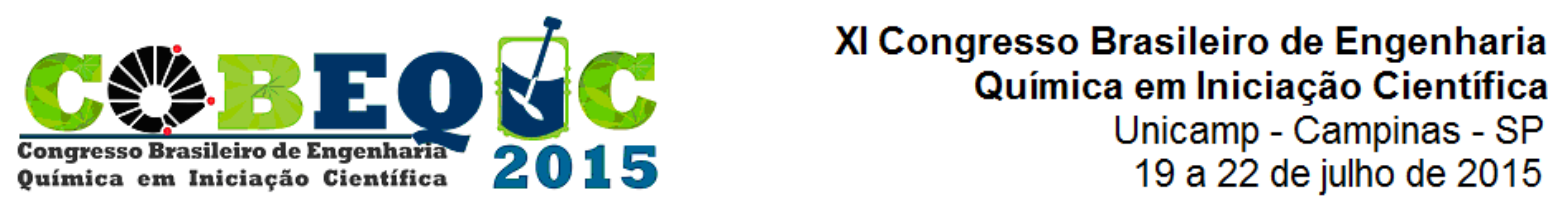

de crescimento $0,0486 \mathrm{~h}^{-1}$ e um menor tempo de geração, além de produtividades e teores lipídicos de 3,29mg/L.h e 18,15\%.

As microalgas constituem uma fonte alternativa potencial na obtenção de bioprodutos. Aliado a obtenção de metabólitos de interesse, com alto valor agregado, está à possibilidade de redução de custos no cultivo destes microrganismos através do uso de compostos de fácil assimilação e baixo custo, como o amido.

\section{REFERÊNCIAS}

BLIGH, E.G.; DYER, W.J. A rapid method of total lipid extration and purification. Com. J. Biochem. Physiol., 37: 911-917, 1959.

BONINI, M. B. E BASTOS, R.G. Biomass production by Aphanothece microscopica and Chlorella vulgaris in heterotrophic growth from glucose. Semina: Ciências Biológicas e da Saúde, Londrina, v. 33, n. 2, p. 151-160, jul./dez. 2012.

CALDEIRA, M. L. D. Produção de SCO (Single Cell Oil) para biodiesel a partir da microalga Chlorella Protothecoides em diversos bioreactores com troca simbiótica de correntes gasosas. Faculdade de Ciências e Tecnologia, Universidade Nova de Lisboa, 2011.

FIDALGO, J. P.; CID, A.; TORRES, A.; SUKENIK, A.; HERRERO, C. Effects of nitrogen source and growth phase on proximate biochemical compostion, lipid classes and fatty acid profile of the marine microalga Isochrysis galbana. Aquacult, v. 166, n. 1-2, p. 105-116, 1998.

FRANCISCO, E. C.; FRANCO, T. T.; MARONEZE, M. M.; ZEPKA, L. Q.; JACOBLOPES, E. Third generation biodiesel production from microalgae. Ciência Rural, Santa Maria, 2015.

FRANCISCO, E. C.; FRANCO, T.T.; WAGNER, R.; JACOB-LOPES, E. Assessment of diffrent carbohydrates as exogenous carbon source in cultivation. Bioprocess BiosystEng, 2014.

HORNES, M.; SILVA, A. G.; MITTERER, M. L.; QUEIROZ, M. I. Influência dos compostos nitrogenados na concentração de proteína da cianobactéria Aphanothece microscopica Nägeli. Ciência e Tecnologia em Alimentos, Campinas, v. 30(2), p. 364$37,2010$.

HUANG, G., CHEN, F., WEI, D., ZHANG, X., CHEN, G. Biodiesel production from microalgal technology. Applied Energy, n. 87, p. 38-46, 2010.

LOURENCCO, S. O.; MARQUEZ, U. M. L.; MANCINI-FILHO, J.; BARBARINO, E.; AIDAR, E. Changes in Biochemical profile of Tetraselmis gracilis I. Compostion of two culture media. Aquacult, v. 148, n. 2-3, p. 153-168, 1997.

MATA, T.M., MARTINS, A. A., CAETANO, N. S. Microalgae for biodiesel prodution and other application: A review. Renew Sustain Energy Rev, v. 14, p. 217-232, 2009. 


\section{Congresso Brasileiro de Engenharia \\ Química em Iniciação Científica \\ Unicamp - Campinas - SP \\ 19 a 22 de julho de 2015}

PEREZ-GARCIA, O.; ESCALANTE, F. M. E.; DE-BASHAN, L. E.; BASHAN, Y. Heterotrophic cultures of microalgae: Metabolism and potential products. Water Research, Oxford, v. 45, p. 11-36, 2011.

QUEIROZ, M. I.; ZEPKA, L. Q.; BASTOS, R. G. Evaluation of single cell protein production by Aphanothece microscopica Nägeli in batch reactor. Food Science and Biotechnology, v. 13, n. 3, p. 130-141, 2004.

QUEIROZ, M. I.; JACOB-LOPES, E. ZEPKA, L. Q.; BASTOS, R. G., GOLDBECK, R. The kinetics of the removal of nitrogen and organic matter from parboiled rice effluent by cyanobacteria in a stirred batch reactor. Bioresource Technology, v. 98, n. 11, p. 2163 2169, 2007.

WEI, A.L.; ZHANG, X.W.; WEI, D.; CHEN, G.; WU, Q.Y.; YANG, S. -T. Effects of cassava starch hydrolysate on cell growth and lipid accumulation of the heterotrophic microalgae Chlorella protothecoides. Journal of Industrial Microbiology and Biotechnology, vol. 36, p. 1383-1389, 2009.

WRIGHT, P. C.; STEVENSON, C.; McEVOY, E.; BURGESS, J. G. Opportunities for marine bioprocess intensification using novel bioreactor design: frequency of barotolerance in microorganisms obtained from surface waters. Journal of Biotechnology, v. 70, p. 343-349, 1999.

ZEPKA, L. Q.; JACOB-LOPES, E.; GOLDBECK, R.; QUEIROZ, M. I. Production and biochemical profile of the microalgae Aphanothece microscopica Nägeli submitted to different drying conditions. Chemical Engineering and Processing, v. 47, n. 8, p. 1311$1316,2008$. 